\title{
Economics of the Oxidative Coupling of Methane as an Add-on Unit for Naphtha Cracking
}

\author{
Jozef H. B.J. Hoebink, Henny M. Venderbosch, Paul C. van Geem, \\ Paul F. van den Oosterkamp and Guy B. Marin*
}

Dedicated to Professor Dr: Manfred Baerns on the occasion of his 60th birthday

The feasibility of methane coupling as an add-on unit to a naphtha cracker was studied. The existing cold box was used for separation of ethylene and unconverted methane, but arrangements were made for separation of the coupling by-products. The cracker's methane was used as a feedstock. The concept is technically and economically feasible at spring 1992 prices, provided the catalyst meets the assumed $30 \%$ conversion and $80 \% \mathrm{C}_{2}$ selectivity.

\section{Scope}

The oxidative coupling of methane provides a potential alternative route for the production of ethylene [1]. A major constraint for application however is the, relatively, low yield. High conversion and low selectivity are unattractive in view of the costs of the feedstocks methane and oxygen. Low conversion and high selectivity on the other hand require an expensive cryogenic separation stage, often designated as a cold box, and extensive process equipment in order to recycle unconverted methane.

The present study considers methane coupling as an add-on unit to a naphtha cracker, which concept holds several promises. Fig. 1 shows the principle schematically. Use of the existing cold box avoids the need for investment in expensive cryogenic equipment, although minor adaptations will be necessary for separation of the coupling by-products carbon dioxide and water. Moreover, use of the cracker's methane as a feedstock allows upgrading of the methane, which has a very high purity compared to methane from natural gas, yet is normally used as a fuel of lower heating value. Finally, such an add-on unit improves the flexibility of the cracker's product distribution, which is of advantage in comparison to a mere capacity enlargement by installing another cracking furnace.

The technical and economic feasibility of this concept was studied against the background of a capacity enlargement of 50000 metric tons/year ethylene via methane coupling for an existing naphtha cracker with a capacity of 500000 metric tons/year ethylene.

\footnotetext{
* Dr. Ir. J. H. B. J. Hoebink, Ir. H.M. Venderbosch and Prof. Dr. Ir G.B. Marin, Eindhoven University of Technology, Laboratorium voor Chemische Technologie, P.O. Box 513, 5600 MB Eindhoven, The Netherlands. Ir. P.C. van Geem, DSM Research B.V., P.O. Box 18, 6160 MD Geleen, The Netherlands. Ir. P.F. van den Oosterkamp, Kinetics Technology International B.V., P.O. Box 86 $2700 \mathrm{AB}$ Zoetermeer, The Netherlands.
}

\section{Methane Coupling Reactor}

Fluidised bed reactors seem most suitable for methane coupling as the reactions are highly exothermal and this type of reactor approaches isothermal operation $[2,3]$. Such a reactor was designed on the basis of a simplified kinetic model $[4,5]$ for a $\mathrm{Li} / \mathrm{MgO}$ catalyst, which is still one of the best performing catalysts. A single pass methane conversion of $30 \%$ and a selectivity of $80 \%$ towards $C_{2}$ products were assumed. The kinetic network consists of parallel routes from methane to carbon oxides and $\mathrm{C}_{2}$ products, and a consecutive step from $\mathrm{C}_{2}$ products to carbon oxides. Carbon monoxide and dioxide are produced in a ratio of $1: 1$, ethane and ethylene in a ratio of $2: 3$.

The well-known two-phase model $[6,7]$ was applied for the reactor design. The assumptions made were: isothermal operation; plug-flow in the bubble phase; ideal mixing in the dense phase and reaction only in the dense phase. The corresponding non-linear algebraic equations were solved, the bed height being determined by the condition of $99 \%$ oxygen conversion above the bed. It was assumed that, at the reactor temperature of $1073 \mathrm{~K}$, the ethane produced was cracked to ethylene in the free-board of the fluidised bed with a conversion of $60 \%$ and a selectivity of $82 \%$.

The methane reactor feed was taken from the top of the naphtha cracker's demethaniser and contains almost 99

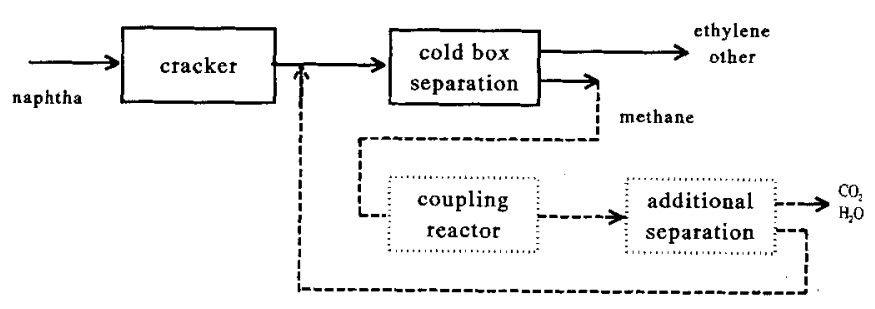

Fig. 1. Schematic representation of methane coupling as an add-on unit to naphtha cracking. Full lines, existing equipment; dotted lines, new equipment. 
$\mathrm{wt} \%$ methane. The oxygen feed is assumed to come from an external supplier.

The results of the design calculations are shown in Figs 2 and 3 and in Table 1 for model parameters, listed in Table 2 , that were obtained from conventional correlations in the literature. Fig. 2 shows a continuing increase of methane conversion and $\mathrm{C}_{2}$ selectivity in higher beds. The phenomenon is probably due to the combination of the assumed ideal-mixing of the dense phase, leading to lower oxygen concentration in larger bed volumes, and the kinetics, which favour $\mathrm{C}_{2}$ products at low methane-to-oxygen ratio. The assumption of ideal dense phase mixing will no longer hold at large reactor height over diameter ratios. The required methane conversion of $30 \%$ and $\mathrm{C}_{2}$ selectivity of $80 \%$ are already met at a bed height of $7 \mathrm{~m}$, but the oxygen conversion is still below $95 \%$. A bed height of $11.5 \mathrm{~m}$ is needed for an oxygen conversion of $99 \%$.

Fig. 3 illustrates that the maximum yield is obtained at a methane-to-oxygen ratio of around 3 , which was applied in the final design, summarised in Table 1. Two fluidised bed reactors are needed for the add-on unit's capacity.

\section{Process Design}

Table 3 compares the compositions of a typical flow into a naphtha cracker's separation section and the flow coming out of the designed methane coupling reactor. The extra carbon monoxide throughput for the cold box resulting from methane coupling is fairly easily removed together with hydrogen as a low value heating gas. The large increase of the methane flow requires adaptation of the heat rating of the demethaniser's reboiler. Ethylene and ethane flow rates increase only marginally. Additional provisions should, however, be made to handle the relatively large amounts of carbon dioxide and water produced by the methane coupling reactions.

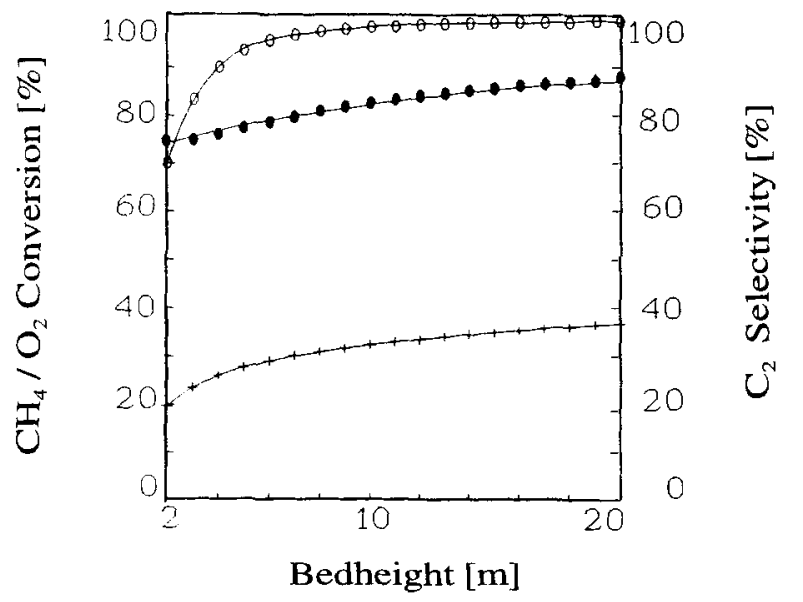

Fig. 2. Conversion and selectivity as function of the reactor height. + Methane conversion, $O$ oxygen conversion, $-\mathrm{C}_{2}$ selectivity.

Table 1. Dimensions and performance of the fluidised bed reactor.

\begin{tabular}{ll}
\hline Ethylene production [Mton/y] & 50000 \\
Reactor height [m] & 11.5 \\
Reactor diameter [m] & 5.7 \\
Reactor temperature [K] & 1073 \\
$\mathrm{CH}_{4}$ Conversion [\%] & 33 \\
$\mathrm{C}_{2} \mathrm{H}_{\mathrm{x}}$ Selectivity [\%] & 84 \\
$\mathrm{O}_{2}$ version [\%] & 99 \\
Reactor duty [MW/reactor] & 18 \\
Number of heat exchanger tubes & 55 \\
Length of the tubes [m] & 10.5 \\
Diameter of the tubes [m] & 0.05 \\
\hline
\end{tabular}

Table 2. Model parameters used in the fluidised bed design.

Minimal fluidisation velocity Superficial velocity Interstitial velocity

Fraction emulsion gas in bed

Max. bubble diameter

Bubble rise velocity

Exchange coefficient

Overall heat transfer coefficient

Cooling temperature

Table 3. Composition of the naphtha cracking and methane coupling effluent.

\begin{tabular}{lrc}
\hline Component & $\begin{array}{l}\text { Naphtha cracking } \\
{[\mathrm{kmol} / \mathrm{h}]}\end{array}$ & $\begin{array}{l}\text { Methane coupling } \\
{[\mathrm{kmol} / \mathrm{h}]}\end{array}$ \\
\hline Hydrogen & 1065 & 44 \\
Carbon monoxide & 7 & 55 \\
Methane & 1773 & 1420 \\
Acetylene & 47 & - \\
Ethylene & 2087 & 230 \\
Ethane & 454 & 46 \\
Propadiene & 49 & - \\
Propylene & 635 & - \\
Propane & 9 & - \\
Butadiene & 190 & - \\
Butane & 148 & 55 \\
Carbon dioxide & 1 & 682 \\
Water & 356 & \\
\hline
\end{tabular}

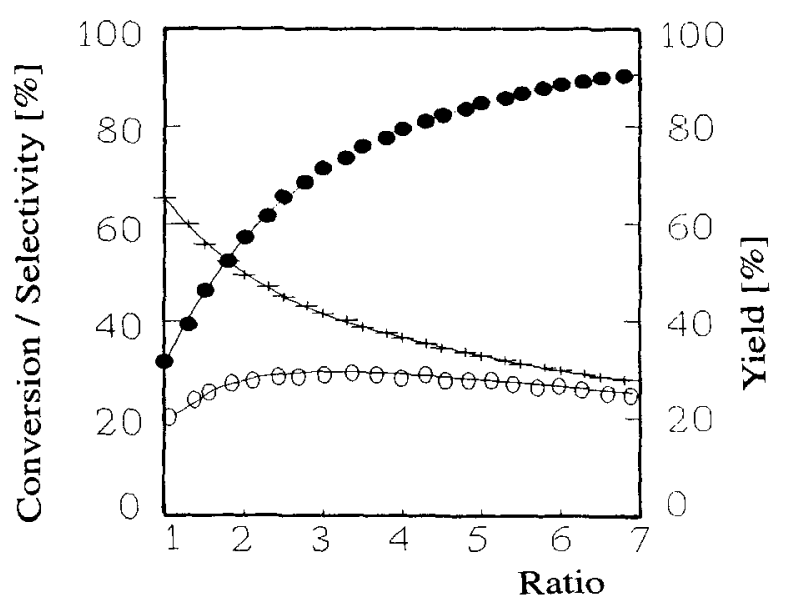

Fig. 3. Reactor performance as function of the molar feed ratio $\mathrm{CH}_{4} / \mathrm{O}_{2}$ at a bed height of $11.5 \mathrm{~m}$. + Methane conversion, $-\mathrm{C}_{2}$ selectivity, $\bigcirc \mathrm{C}_{2}$ yield. 
The new separation section for the methane coupling reactor was designed with the aid of the flowsheet simulation package Chemcad [8] and is shown in Fig. 4. The product stream leaves the reactor at $1023 \mathrm{~K}$ and 1 bar and enters the separation section as stream 1 . The stream is cooled down to $298 \mathrm{~K}$ and condensed water is separated in a knock-out drum. The compression to 10 bar before entering the MEA tower via stream 12 occurs in three steps with interstage cooling to $298 \mathrm{~K}$ and water removal. In the MEA tower carbon dioxide is removed from the product stream with a 17 wt $\%$ aqueous monoethanolamine (MEA) solution. The liquid stream 21 leaving the MEA tower has a temperature of $379 \mathrm{~K}$ on entering the MEA regeneration section, where carbon dioxide is removed via steam-stripping at $1.5 \mathrm{bar}$. The stripper's bottom stream 22 is cooled and recycled to the MEA tower as stream 27. The top stream 28 from the stripper is cooled and liquid and gas are separated in a knockout drum. The liquid stream 30 , containing mainly water, is recycled to the MEA regeneration tower. Downstream of the MEA tower the top product stream 13 is compressed to 36 bar in two steps with interstage cooling and water removal. The resulting stream 19 is dried with molecular sieves by two dryers in parallel.

The product stream 20 enters the separation section (not shown) of the naphtha cracker right into the cold box, i.e. downstream of the primary fractionator, quench column and their corresponding MEA tower and dryer.

\section{Methods of Economic Evaluation}

The fixed capital investment for the designed plant was estimated as a so-called budget estimate via two methods, which both are claimed to have an accuracy of $\pm 25 \%$.

1. The specific factor method [9] as developed by the Dutch Association of Cost Engineers (DACE) for estimating battery limits investments distinguishes five groups of process equipment, each with factors depending on the free-onboard (FOB) equipment cost in the base year 1981. Multiplication of the bare equipment cost by this specific factor gives the fixed capital investment without allowance for contingency. The method involves estimation of the bare equipment costs in 1981 and updating by means of cost indices. A $5 \%$ contingency was added to obtain the total capital investment.

2. The Miller method [10] is a factored estimation, based on the sum of the free-on-board costs of the main process items (MPI). Other cost items are expressed as percentages of MPI, which are recommended as low, average or high esti-

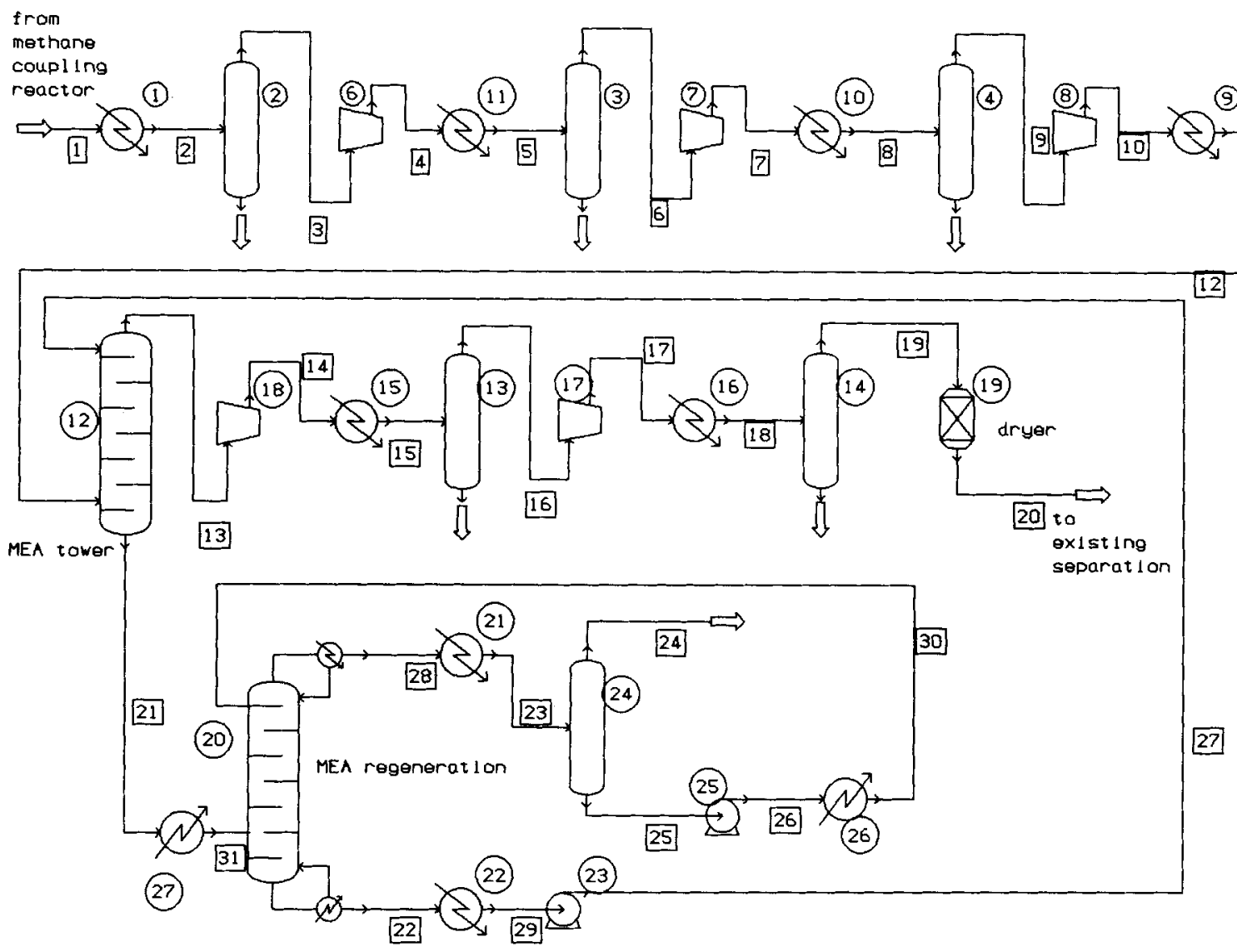

Fig. 4. Additional separation section for treatment of the coupling reactor's effluent, when incorporating oxidative coupling of methane as an addon unit in an existing naphtha cracking plant. Circles, equipment numbers; squares, stream numbers. 
mation factors. In this study all factors were set at the advised average values [10] with some exceptions. The miscellaneous unlisted equipment (MUE) was fixed at the highest value of $20 \%$ because the flowsheet is in a rather preliminary stage. Installation of basic equipment was set at the average value for mild steel equipment. The foundation was taken at an average value with addition of $25 \%$ for piling. For piping a value of $33 \%$ was chosen because most streams contain gases. Insulation was set at a high value owing to the high temperatures involved. Electrical equipment is estimated as comparable to petrochemical plants. Instrumentation was chosen at a high level, because it has developed enormously during the past decades. For buildings and corresponding services average values were chosen with the exception of sprinklers, which were chosen high. The total of factors, leading to the direct costs of battery limits, is $90 \%$.

Factors for other direct costs such as storage and handling, utilities and services were taken low at $12 \%$, because the plant is an additional unit on an existing site.

Indirect costs and contingencies were accounted for by a factor of $25 \%$ and $5 \%$, respectively, of the total direct costs. The total capital investment was obtained by adding the working capital, estimated as the revenues of sales during two months. The costs of land were not taken into account.

FOB costs for equipment were determined with the program Chemcost [11] and were partly checked by KTI. The cost estimation of the methane coupling fluidised bed reactor is based on a kettle reboiler made of cast iron. Heat exchanger costs are based on the heat transfer surface area, calculated from the heat duty and the logarithmic driving force, while adopting common values for the heat transfer coefficients. A maximum surface area of $1000 \mathrm{~m}^{2}$ was assumed. Therefore the heat exchanger for recovery of the sensible heat from the coupling reactor's product stream was split up into 42 items. For this particular heat exchanger stainless steel was chosen, all the others being made from carbon steel. Refrigeration was incorporated to provide cooling that could not be achieved by process water.

All compressors were considered as motor driven centrifugal compressors. Flash drums were calculated as being positioned vertically, and made of carbon steel. The $\mathrm{CO}_{2}$ absorber is a tray column, made of carbon steel. The column with a diameter of $1.8 \mathrm{~m}$ and height of $12.5 \mathrm{~m}$ contains 25 trays. For calculation of the costs of the MEA stripper a tray absorber with reboiler, all made of carbon steel was chosen. The diameter of the column is $1.6 \mathrm{~m}$, the height is $12.8 \mathrm{~m}$ and the column contains 26 trays. The dryers contain molecular sieves as packing.

A summary of all major process items and their costs is given in Table 4. Column 4 of this table specifies the FOB costs as used in Miller's method. Column 5 of the table concerns the fixed capital investment for installed equipment according to the DACE method.
Table 4. Summary of all major process items and their costs.

\begin{tabular}{|c|c|c|c|c|}
\hline $\begin{array}{l}\text { Item } \\
\text { no. }\end{array}$ & Process item & Amount & $\begin{array}{l}\text { Item cost, } \\
\text { Miller, } \\
10^{3} \$\end{array}$ & $\begin{array}{l}\text { Fixed capital } \\
\text { investment per } \\
\text { item, DACE, } 10^{3} \$\end{array}$ \\
\hline & Reactor & 2 & 4298 & 9874 \\
\hline 1 & Heat exchanger & 42 & 731 & 2193 \\
\hline 11 & Heat exchanger & 1 & 55 & 197 \\
\hline 9,10 & Heat exchanger & 4 & 48 & 176 \\
\hline \multicolumn{5}{|l|}{15,16} \\
\hline 27 & Heat exchanger & 1 & 25 & 98 \\
\hline 21 & Heat exchanger & 1 & 31 & 122 \\
\hline 22 & Heat exchanger & 1 & 83 & 274 \\
\hline \multirow[t]{2}{*}{26} & Heat exchanger & 1 & 1 & 7 \\
\hline & Cooling machine & 1 & 248 & 793 \\
\hline $\begin{array}{r}6,7 \\
8,18\end{array}$ & Gas compressor & 4 & 524 & 1569 \\
\hline 17 & Gas compressor & 1 & 290 & 929 \\
\hline 2 & Flash drum & 1 & 43 & 229 \\
\hline $3,4,5$ & Flash drum & 5 & 21 & 133 \\
\hline \multicolumn{5}{|c|}{13,14} \\
\hline 24 & Flash drum & 1 & 8 & 61 \\
\hline 12 & $\mathrm{CO}_{2}$ absorber & 1 & 87 & 453 \\
\hline 20 & $\begin{array}{l}\text { Distillation } \\
\text { column }\end{array}$ & 1 & 53 & 300 \\
\hline 19 & Dryer & 2 & 42 & 251 \\
\hline 25 & Pump & 1 & 1 & 8 \\
\hline 23 & Pump & 1 & 7 & 31 \\
\hline Miller & Total MPI cost & & 42707 & \\
\hline DACE & $\begin{array}{l}\text { Total Fixed } \\
\text { Capital }\end{array}$ & & & 123503 \\
\hline
\end{tabular}

Table 5. Percentages used in product cost estimation [12].

\begin{tabular}{llc}
\hline Cost-type & Basis & Factor \\
\hline Operating labour & fixed capital & 10 \\
Supervision & operating labour & 10 \\
Utilities & raw material cost & 10 \\
Maintenance & fixed capital & 2 \\
Operating supplies & maintenance & 10 \\
Laboratory charges & operating labour & 10 \\
Patents \& Royalties & & 0 \\
Overhead & operating labour & 60 \\
Local taxes & & 0 \\
Insurance & fixed capital & 0.4 \\
Administrative & operating labour & 25 \\
Disiribution \& Sales & total product cost & 5 \\
R\&D & total expenses & 5 \\
\hline
\end{tabular}

Table 6. Costs and credits in the product cost calculation (spring 1992).

\begin{tabular}{lccc}
\hline Item & $\begin{array}{l}\text { Total amount } \\
{[\mathrm{kton} / \mathrm{yr}]}\end{array}$ & $\begin{array}{l}\text { Prize } \\
{[\$ / \text { ton] }}\end{array}$ & $\begin{array}{l}\text { Total } \\
{\left[10^{6} \$ / \mathrm{y}\right]}\end{array}$ \\
\hline Catalyst & 0.136 & 3450 & 0.5 \\
Methane & 78 & 163 & 12.7 \\
Oxygen & 108 & 35.5 & 3.8 \\
Ethylene & 50.0 & 485 & 24.2 \\
Carbon dioxide & 19.4 & 250 & 4.9 \\
Energy & 18.4 [Mwatt] & $0.05[\$ / \mathrm{kWh}]$ & 7.4 \\
\hline
\end{tabular}

A standard method was applied for product cost calculation [12]. Details of the various cost items are presented in Table 5 . The amounts and prices of reactants and products are shown in Table 6 . The catalyst costs refer to depreciation of 
the catalyst after one year. The market prices of most chemicals were taken from Chemical Marketing Reporter. All prices refer to the spring of 1992 .

\section{Discussion}

The total capital investment according to Miller's method amounts to $\$ 144$ million or $\$ 130$ million according to DACE. The agreement is quite satisfactory in view of the claimed accuracy of the methods. Based on the $\$ 144$ million investment, the ethylene cost price is $\$ 1423$ per ton of ethylene, or $\$ 1177$ per ton of ethylene taking by-product credits into account.

However, when considering the investment costs in more detail, see Table 4, the major cost item concerns the 42 heat exchangers intended to recover the sensible heat from the product stream leaving the methane coupling reactor. It is rather obvious that such an investment of $\$ 92$ millions, based on DACE, is not justified to save $1.2 \times 10^{8} \mathrm{~kJ} / \mathrm{h}$ latent heat, which corresponds to 20000 tons of methane per year, or $\$ 3$ millions per year.

Without any latent heat recovery the total capital investment amounts to $\$ 45$ millions or $\$ 33$ millions depending upon the method used, if the minor investment for killing the latent heat is neglected. The lowest net ethylene cost price, would then amount to $\$ 348$ per ton of ethylene, which should be compared to the spring 1992 market price of $\$ 485$ per ton of ethylene. This represents a return of investment ROI between 15 and $20 \%$.

A comparison of the present study with a naphtha cracker capacity enlargement by installing an additional cracking furnace is not straightforward since tactical considerations like flexibility of the product distribution cannot be weighed. Installation of an extra furnace also requires adaptations in the cold box section, but they differ from the case of a methane coupling add-on unit. Such an enlargement is usually carried-out as a revamp of the complete plant, meaning that the required total capital investment strongly depends on decisions whether or not to replace malfunctioning or depreciated equipment. Moreover spare capacity in parts of a plant is usually taken away in practice by debottlenecking and optimisation of the operating conditions with respect to the design specification. In view of these considerations the total capital investment for such a revamp is estimated to exceed $\$ 45$ millions in most cases.

\section{Conclusions}

The application of methane oxidative coupling as an add-on unit to enlarge the ethylene capacity of a naphtha cracker is a technically and economically feasible concept provided the catalyst meets the assumed single pass conversion of $30 \%$ and selectivity of $80 \%$ towards $C_{2}$-products. It may use the existing cryogenic separation train of the naphtha cracker for purification of the ethylene produced via coupling, and requires only an additional separation section to remove the coupling by-products carbon dioxide and water. Recovery of the sensible heat from the coupling reactor's outlet stream is not worthwhile for purely economic reasons, despite the large amount of heat involved.

\section{Acknowledgement}

This work is funded in part by the Commission of the European Communities in the framework of the Joule program, subprogram Energy from Fossil Sources, Hydrocarbons, under contract JOUF-0044. Other financial support was granted by NOVEM.

Received: January 17 (1994) [CET 627]

\section{References}

[1] Baerns, M., paper presented at NATO-ASI, London, Ontario, Canada, Aug. 1991.

[2] Mleczko, L., Andorf, R., Baerns, M., paper presented at A.I.Ch.E. Annual Meeting, Chicago, 1990.

[3] Mleczko, L., Rothaemel, M., Andorf, R., Baerns, M., paper presented at 7 th International Fluidization Conference, Broad Beach, Australia, May 3-8, 1992.

[4] Geerts, J.W.M.H., Ph.D. Thesis, Eindhoven University of Technology, Eindhoven, 1990.

[5] Geerts, J.W.M.H., Hoebink, J.H.B. J., van der Wiele, K., Ethylene from natural gas, proven and new technologies, in: Novel production methods for ethylene, light hydrocarbons and aromatics (L.F. Albright et al., Eds), M. Dekker Inc., New York 1992.

[6] May, W.G., Chem. Eng Prog. 55 (1959) pp. $49-56$.

[7] van Deemter, J.J., Chem. Eng Sci. 13 (1961) pp. 143-154.

[8] Chemcad flowsheet simulation, Chemstation Inc., Houston, 1990.

[9] Handbook Cost Engineers, Dutch Association of Cost Engineers, Samson Uitgeverij, Alphen aan de Rijn, 1989.

[10] Miller, C. A., Chem. Eng 72 (1965) Sept. 13, pp. 226-236.

[11] Chemcost software, COADE, Houston 1989.

[12] Peters, M.S., Plant design and economics, McGraw-Hill, New York 1980. 